\title{
Turismo de observação de aves nas Unidades de Conservação da região da llha do Bananal, Cantão (TO)
}

\author{
Birdwatching tourism in the Protected Area of the Ilha do \\ Bananal, Cantão Region (TO, Brazil)
}

\author{
Renato Torres Pinheiro
}

RESUMO: A observação de aves é um dos segmentos do ecoturismo que tem atraido mais praticantes no Brasil e no mundo, sendo considerada de baixo impacto ambiental e provedora de boa rentabilidade econômica. A notável variedade de ambientes encontradas no país e a rica avifauna associada a eles tem propiciado atividades de observação de aves em todas as regiões e grande parte desta biodiversidade é encontrada nas unidades de conservação, porém poucas estão estruturadas para receber este público. Ainda que grande parte do conhecimento ornitológico seja obtido por ornitólogos, é crescente o número de novos registros efetuados por observadores de aves, que exercem a chamada ciência cidadã. Este trabalho apresenta uma listagem da avifauna da região da llha do Bananal/Cantão Tocantins, um dos principais destinos para observação de aves no país, atualizada a partir de registros documentados realizados por observadores de aves e analisa o importante papel da ciência cidadã na aquisição de informações relevantes para o conhecimento e conservação da avifauna regional.

PALAVRAS CHAVE: Observação de Aves; Ciência Cidadã; Conservação; Ecoturismo.

\section{ABSTRACT}

Birding is one of the segments of ecotourism that has attracted more practitioners in Brazil and the world, being considered of low environmental impact and proving good economic profitability. The remarkable variety of environments found in the country and the rich avifauna associated with them has provided bird watching activities in all regions and much of this biodiversity is found in conservation units, but few are structured to receive this public. Although great part of the ornithological knowledge is obtained by ornithologists, the number of new registries realized by birdwatchers, who exercise the call citizen science, is increasing. This work presents a bird list of the Bananal Island / Cantão region, Tocantins state, one of the main destinations for bird observation in the country, updated from documented records made by birdwatchers and analyzes the important role of citizen science in the acquisition of relevant information for the knowledge and conservation of the regional avifauna.

KEYWORDS: Birdwatching; Citizen Science; Conservation; Ecotourism. 


\section{Introdução}

A observação de aves em seu meio natural ou birdwatching é uma atividade ecoturística de recreação ao ar livre, educativa e alinhada com a preservação ambiental (McFARLANE, 1994; FARIAS, 2007). Nela o turista faz observações das aves com binóculos e/ou telescópios, podendo efetuar registros fotográficos e sonoros das espécies, tendo como variantes, a pintura e a ilustração da natureza (PIVATTO et al., 2007).

A observação da natureza, assim como a observação de aves faz parte do cotidiano de muitos povos estando retratada na cultura tradicional por meio de pinturas, esculturas, vestimenta, poesias, canções e danças (MOSS, 2004). Ainda que a observação de aves amadora não esteja oficialmente documentada, historicamente, o interesse pela natureza, em especial pelas aves, tinha se popularizado na Inglaterra antes do século XIV, no entanto, a observação de aves organizada, da maneira que a conhecemos hoje, nasceu nos Estados Unidos por volta do ano 1870, mas somente a partir da década de 1960, quando as viajens aéreas tornaram-se mais acessíveis surgiram empresas especializadas em turismo ornitológico, abrindo caminho para uma nova modalidade turística (MOSS, 2004).

A observação de aves como atividade turística vem sendo praticada há décadas em países do hemisfério norte, mas apenas recentemente vem se destacando no cenário turístico brasileiro (PIVATTO et al., 2007; ALEXANDRINO et al., 2012). Considerada um seguimento do turismo ecológico, a observação de aves é uma das atividades ecoturísticas mais difundidas e praticadas no mundo, possuindo características conservacionistas, educativas e sócio-econômicas, que buscam a conscientização ambiental, promove o uso sustentável dos recursos naturais, é economicamente viável e insere a comunidade local (RUSCHMANN, 1997; FARIAS, 2007; PIVATTO et al., 2007, FARIAS; CASTILHO, 2007).

Reconhecido como o país com maior diversidade biológica mundial (LEWINSON; PRADO, 2000), o Brasil ocupa o segundo lugar em riqueza de aves, com 1.919 espécies, o que corresponde a aproximadamente $20 \%$ de todas as espécies de aves do planeta e o primeiro das Américas em número de aves endêmicas com 189 espécies, ou seja, quase 10\% destas espécies são exclusivas do nosso país (PIACENTINI et al., 2015). Essa grande diversidade de aves e seus endemismos são um recurso imcomparável que pode alavancar o ecoturismo e a economia nacional (FARIAS, 2007).

Por ser uma atividade de baixo impacto ambiental e boa rentabilidade econômica, muitos municípios e investidores locais estão buscando atrair este público. Porém, a integridade do ambiente e das aves são fundamentais para o desenvolvimento deste seguimento turístico. Neste sentido, a população local e empreendedores oriundos de localidades propícias para a observação de aves, tem utilizado essa riqueza natural como um recurso econômico, agregando valor aos produtos e serviços turísticos ofertados, gerando renda e melhorando a qualidade de vida de seus habitantes (DIAS; FIGUEIRA, 2010). 
A grande variedade de ambientes encontradas no país e a rica avifauna associada a eles tem propiciado atividades de observação de aves em todas as regiões e biomas brasileiros, e parte expressiva dessa biodiversidade está representada e resguardada pelas unidades de conservação. Neste cenário, a região Amazônica se destaca como uma das mais procuradas e tem se consolidado como um importante destino de observadores de aves e de natureza em geral. De acordo com Plácido (2017), duas características do bioma Amazônia explanam o crescente interesse de turistas pela região: o fato da região abrigar a maior diversidade de flora e fauna e de ser o bioma com maior diversidade de aves, aproximadamente 1.300 espécies, o que explica o crescente número de destinos para observação de aves em toda a Amazônia. Nesta região, investimentos tem sido feitos na construção ou melhoria de infraestrutura como hospedagem, trilhas e torres de observação, tornando-se locais imprescindíveis para a prática da observação de aves no Brasil.

As unidades de conservação cumprem diversas funções das quais seus benefícios podem ser aproveitados por divesas esferas, incluindo setores econômicos (MEDEIROS et al., 2011) e se destacado como destinos preferenciais para a prática da observação de aves (FIGUEIREDO, 2003; BRASIL, 2005; ALMEIDA et al., 2016), no entanto, apenas umas poucas unidades de conservação incluem a observação de aves como uma atividade turística. Em 2008, o Ministério do Meio Ambiente, o Instituto Chico Mendes de Conservação da Biodiversidade e a EMBRATUR, lançaram o Programa de Turismo nos Parques, baseando-se em estudos realizados no Plano de Ação para Estruturação e Promoção do Turismo nos Parques Nacionais, estabelecendo prioridades em 25 Parques Nacionais. Destes apenas três, o Parque Nacional Marinho de Abrolhos, Parque Nacional de Aparados da Serra e o Parque Nacional do Jaú, fazem menção sobre a observação de aves (BRASIL, 2008).

A região da llha do Bananal/Cantão, localizada no centro-oeste do Tocantins, situa-se na faixa de transição entre o Cerrado e Amazônia formando um área ecotonal de grande diversidade biológica. Seu reconhecimento como área de elevada diversidade biológica está referendado por um complexo de unidades de conservação que incluem o Parque Nacional do Araguaia (Sitio Ramsar), o Parque Estadual do Cantão, a Área de Proteção Ambiental Ilha do Bananal/Cantão e as Reservas Particulares do Patrimônio Natural Canguçu, Bico do Javaés, Água Bonita e Sonhada, juntas integram o Corredor Ecológico Araguaia Bananal. Levantamentos realizados na região identificaram 415 espécies de aves, sendo quatro quase ameaçadas e oito ameaçadas de extinção, 27 endêmicas Amazônicas e nove endêmicas do Cerrado, além de onze espécies migratórias neárticas (MMA, 2001; PINHEIRO, 2007; PINHEIRO; DORNAS, 2009a,b; CROZARIOL; LEITE, 2010; DORNAS; PINHEIRO, 2011), tornando-se o destino preferêncial para observação de aves no Tocantins e um dos principais do Brasil.

A exploração sustentável das aves brasileiras é necessário para garantir a sua conservação, neste sentido, a observação de aves se enquadra na categoria ciência cidadã onde amadores, voluntários e 
entusiastas em ciência contribuem voluntariamente com a produção de informações científicas a partir de informações geradas durante as visitas a campo (MOURÃO, 2004; PIVATTO; SABINO, 2005; COMANDULLI et al., 2016). Os observadores de aves fornecem uma informação valiosa sobre a avifauna, auxiliando no manejo dos recursos naturais, conservação de espécies e promoção do turismo local (McFARLANE; BOXAL, 1996; PLÁCIDO, 2017). Diante na importância cada vez maior dos observadores de aves para o ecotursimo e para a ciência, o presente trabalho apresenta uma listagem da avifauna da região da llha do Bananal/Cantão - Tocantins, atualizada a partir de registros documentados realizados por observadores de aves e analisa o importante papel da ciência cidadã na aquisição de informações relevantes para o conhecimento e conservação da avifauna regional.

\section{Materiais e métodos}

\section{Área de estudo}

Localizada no centro-oeste do Tocantins, a região da llha do Bananal/Cantão (Figura 1), abrange a planície do rio Araguaia, com altitude média de $150 \mathrm{~m}$, clima úmido com moderada ou nula deficiência hídrica, temperatura média de $28^{\circ} \mathrm{C}$ e pluviosidade anual de $2.100 \mathrm{~mm}$. (SEPLAN, 2008). A região está na transição entre a Floresta Amazônica e o Cerrado, formando um mosaico de ecossistemas de grande relevância biológica e ecológica, protegidos por cinco unidades de conservação, duas da categoria de proteção integral: o Parque Nacional do Araguaia e o Parque Estadual do Cantão, e cinco da categoria de uso sustentável: a Área de Proteção Ambiental llha do Bananal/Cantão e as Reservas Particulares do Patrimônio Natural Canguçu, Bico do Javaés, Água Bonita e Sonhada que juntas abrangem 23.296,12 $\mathrm{Km}^{2}$ e ocupam parcialmente ou integralmente nove municípios: Araguacema, Dois Irmãos do Tocantins, Abreulândia, Caseara, Divinópolis do Tocantins, Marianópolis do Tocantins, Monte Santo do Tocantins, Chapada de Areia e Pium (CNUC, 2019, SEMARH, 2019). A vegetação é de transição caracterizada por formações típicas do Cerrado com elementos de Floresta Ombrófila do Bioma Amazônico (SANTOS; LOLIS, 2007). 


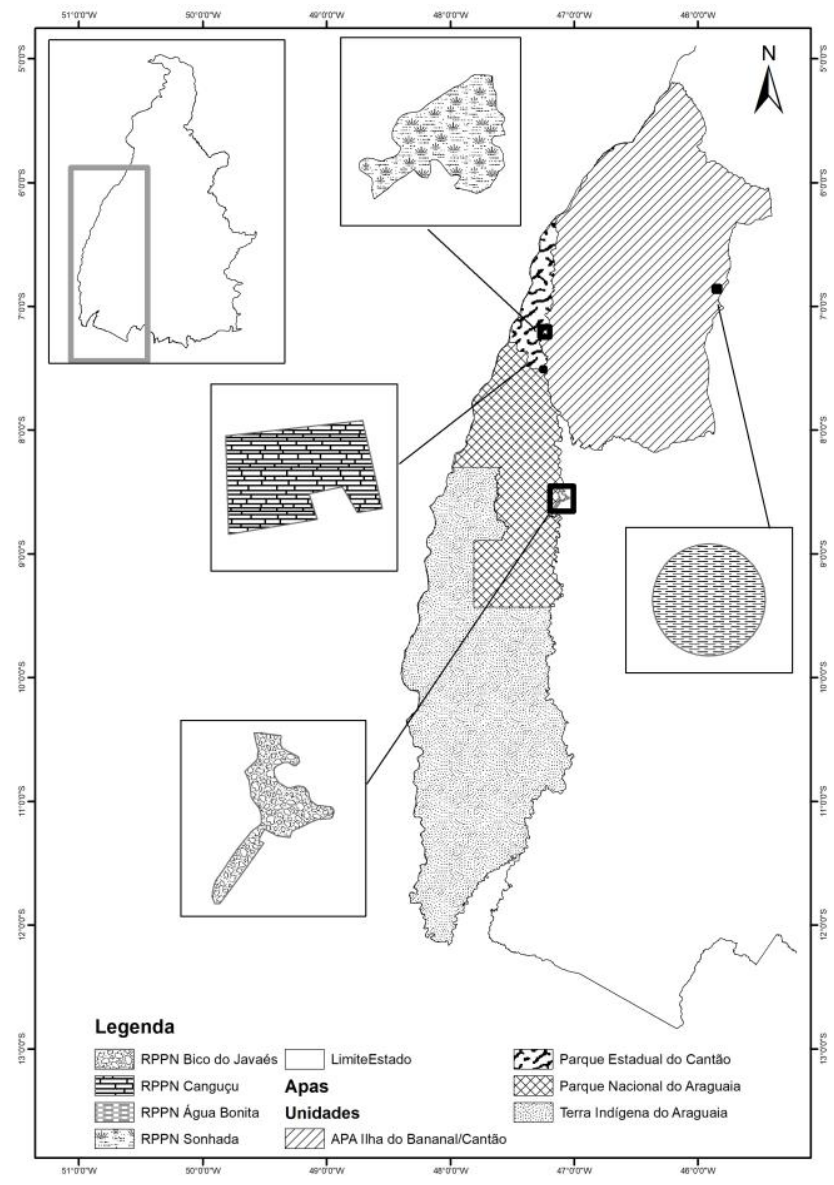

Figura 1: Unidades de Conservação da região centro-oeste do Estado do Tocantins. Fonte: Elaborado a partir de SEPLAN (2012); CNUC (2016); SEMARH (2016).

Figure 1: Conservation units of the central-western region of the State of Tocantins. Source: Prepared from SEPLAN (2012); CNUC (2016); SEMARH (2016).

\section{Metodologia}

Para compilação dos dados referentes a riqueza de aves na região da Ilha do Bananal/Cantão realizou-se busca de registros na literatura, sendo verificados artigos científicos que formaram a base de dados de cunho científico. As informações oriundas dos observadores de aves e que compuseram o acervo classificado como ciência cidadã foram obtidas no site wikiaves (www.wikiaves.com.br), plataforma on-line que reúne a maior comunidade de observadores de aves do Brasil e que colabora com a provisão de dados atualizado sobre as aves brasileiras (DIAS, 2011). Apesar da presença de outras plataformas optou-se por utilizar apenas os dados do wikiaves por este trazer fotos e sons das espécies, além de um conjunto de regras com critérios para publicação e a participação de moderadores que avaliam previamente o material enviado para publicação. Para validação das espécies foram considerados os registros visuais e/ou sonoros em pelo menos um dos municipios da área de estudo.

As espécies que compõe a lista das aves da região da llha do Bananal/Cantão foram obtidas em: MMA, 2001; TOCANTINS 2004; PINHEIRO, 2007; PINHEIRO; DORNAS, 2008; PINHEIRO; DORNAS, 
2009a,b; CROZARIOL; LEITE, 2010; DORNAS; PINHEIRO, 2011. A nomenclatura seguiu a lista comentada das aves do Brasil pelo Comitê Brasileiro de Registros Ornitológicos (PIACENTINI et al., 2015), espécies ameaçadas brasileiras segundo a Lista Nacional da Fauna Brasileira Ameaçada de Extinção (MMA, 2014), espécies ameaçadas globalmente segundo a lista vermelha das espécies ameaçadas globalmente da União Internacional para Conservação da Natureza (IUCN, 2018), endemismos Amazônicos segundo Stotz et al. (1996), endemismos do Cerrado (SILVA, 1997; SILVA; SANTOS, 2005) e espécies encontradas no Cerrado com centro de distribuição na Amazônia segundo Silva (1996).

\section{Resultados}

Com base nas publicações científicas foram identificadas 415 espécies referentes a 71 familias nas unidades de conservação e municípios que compõe a área de estudo. Os registro oriundos do site Wikiaves incluiram 63 novas espécies à lista, um acréscimo de 15,18\%, totalizando 478 espécies na lista final, o que corresponde a $76,11 \%$ do total de espécies que ocorrem no Tocantins (DORNAS, 2009).

A região se destaca pelo número de espécies endêmicas, sendo 27 endemismos Amazônicos e nove endemismos do Cerrado. Com os registros dos observadores de aves, subiu para 41 o número de endemismos Amazônicos, um incremento de $51,85 \%$ e para dez os endemismos do Cerrado. A região da llha do Bananal/Cantão se destaca ainda pela presença de espécies migratórias neárticas, oriundas do hemisfério norte, sendo identificadas doze espécies (Tabela 1).

Quanto ao status de conservação, na região foram registradas sete espécies ameaçadas: Tinamus tao, Penelope pileata, Penelope ochrogaster, Harpia harpyja, Lophornis gouldii, Celeus obrieni, Cercomacra ferdinandi e Serpophaga hypoleuca que se enquadram na categoria Vulnerável e Urubitinga coronata na categoria Em Perigo (MMA, 2014; IUCN, 2018), além de sete globalmente quase ameaçadas, Rhea americana, Neochen jubata, Harpia harpyja, Spizaetus ornatus, Primolinus maracana, Alipiopsitta xanthops e Charitospiza eucosma (IUCN, 2018). Com a colaboração dos observadores de aves foram acrescentadas mais três espécies à lista de espécies ameaçadas, que incluem, Neomorphus geoffroyi e Dendrocolaptes retentus como Vulnerável (MMA, 2014) e Pyrrhura amazonum como globalmente Em Perigo (IUCN, 2018), além de quatro globalmente quase ameaçadas, Zebrilus undulatus, Ramphastus tucanus, Porphyrospiza caerulescens e Neothraupis fasciata (IUCN, 2018). A lista final soma 12 espécies com algum grau de ameaça de extinção em nível nacional e global e 11 espécies globalmente quase ameaçadas (Tabela 1). 
Tabela 1: Espécies de aves registradas nas unidades de conservação da região da llha do Bananal/Cantão, região centro-oeste do estado do Tocantins.

Table 1: Species of birds recorded in the conservation units of the Bananal Island/Cantão, central-western region of the state of Tocantins.

\begin{tabular}{|c|c|c|c|c|}
\hline Táxons & Nomes comúns & $\begin{array}{c}\text { UCs Ilha do } \\
\text { Bananal/ } \\
\text { Cantão }\end{array}$ & Wikiaves & Status \\
\hline \multicolumn{5}{|l|}{ Rheidae } \\
\hline Rhea americana & & $x$ & & $N T^{B}$ \\
\hline \multicolumn{5}{|l|}{ Tinamidae } \\
\hline Tinamus tao & azulona & $x$ & & VUA,B \\
\hline Crypturellus cinereus & inambu-pixuna & $x$ & & ENA \\
\hline Crypturellus soui & tururim & $x$ & & \\
\hline Crypturellus undulatus & jaó & $x$ & & \\
\hline Crypturellus strigulosus & inambu-relógio & & $x$ & \\
\hline Crypturellus parvirostris & inambu-chororó & $x$ & & \\
\hline Rhynchotus rufescens & perdiz & $x$ & & \\
\hline Nothura maculosa & codorna-amarela & & $\mathrm{x}$ & \\
\hline \multicolumn{5}{|l|}{ Anhimidae } \\
\hline Anhima cornuta & anhuma & $x$ & & \\
\hline \multicolumn{5}{|l|}{ Anatidae } \\
\hline Dendrocygna bicolor & marreca-caneleira & $x$ & & \\
\hline Dendrocygna viduata & irerê & $x$ & & \\
\hline Dendrocygna autumnalis & marreca-cabocla & $x$ & & \\
\hline Neochen jubata & pato-corredor & $x$ & & NTB \\
\hline Cairina moschata & pato-do-mato & $x$ & & \\
\hline Amazonetta brasiliensis & ananaí & $x$ & & \\
\hline \multicolumn{5}{|l|}{ Cracidae } \\
\hline Penelope superciliaris & jacupemba & $x$ & & \\
\hline Penelope pileata & jacupiranga & $x$ & & VUA,B \\
\hline
\end{tabular}




\begin{tabular}{|c|c|c|c|c|}
\hline Táxons & Nomes comúns & $\begin{array}{c}\text { UCs Ilha do } \\
\text { Bananal/ } \\
\text { Cantão }\end{array}$ & Wikiaves & Status \\
\hline Penelope ochrogaster & jacu-de-barriga-castanha & $x$ & & $\begin{array}{l}\text { VUA,B, } \\
\text { ENC }\end{array}$ \\
\hline Aburria cujubi & cujubi & $x$ & & \\
\hline Crax fasciolata & mutum-de-penacho & $x$ & & \\
\hline \multicolumn{5}{|l|}{ Podicipedidae } \\
\hline Tachybaptus dominicus & mergulhão-pequeno & & $x$ & \\
\hline \multicolumn{5}{|l|}{ Ciconiidae } \\
\hline Ciconia maguari & maguari & & $x$ & \\
\hline Jabiru mycteria & tuiuiú & $x$ & & \\
\hline Mycteria americana & cabeça-seca & $x$ & & \\
\hline \multicolumn{5}{|l|}{ Phalacrocoracidae } \\
\hline Nannopterum brasilianus & biguá & $x$ & & \\
\hline \multicolumn{5}{|l|}{ Anhingidae } \\
\hline Anhinga anhinga & biguatinga & $x$ & & \\
\hline \multicolumn{5}{|l|}{ Ardeidae } \\
\hline Tigrisoma lineatum & socó-boi & $x$ & & \\
\hline Agamia agami & garça-da-mata & $x$ & & \\
\hline Cochlearius cochlearius & arapapá & $x$ & & \\
\hline Zebrilus undulatus & soco.-zigue-zague & & $x$ & $\begin{array}{l}N^{B} \\
\text { ENA }\end{array}$ \\
\hline Nycticorax nycticorax & socó-dorminhoco & $x$ & & \\
\hline Butorides striata & socozinho & $x$ & & \\
\hline Bubulcus ibis & garça-vaqueira & $x$ & & \\
\hline Ardea cocoi & garça-moura & $x$ & & \\
\hline Ardea alba & garça-branca & $x$ & & \\
\hline Syrigma sibilatrix & maria-faceira & $x$ & & \\
\hline Pilherodius pileatus & garça-real & $x$ & & \\
\hline Egretta thula & garça-branca-pequena & $x$ & & \\
\hline
\end{tabular}




\begin{tabular}{|c|c|c|c|c|}
\hline Táxons & Nomes comúns & $\begin{array}{c}\text { UCs Ilha do } \\
\text { Bananal/ } \\
\text { Cantão }\end{array}$ & Wikiaves & Status \\
\hline Egretta caerulea & garça-azul & $x$ & & \\
\hline \multicolumn{5}{|l|}{ Threskiornitidae } \\
\hline Mesembrinis cayennensis & coró-coró & $x$ & & \\
\hline Phimosus infuscatus & tapicuru & $x$ & & \\
\hline Theristicus caudatus & curicaca & $x$ & & \\
\hline Platalea ajaja & colhereiro & $x$ & & \\
\hline \multicolumn{5}{|l|}{ Cathartidae } \\
\hline Cathartes aura & urubu-de-cabeça-vermelha & $x$ & & \\
\hline Cathartes burrovianus & urubu-de-cabeça-amarela & $x$ & & \\
\hline Cathartes melambrotus & urubu-da-mata & & $x$ & ENA \\
\hline Coragyps atratus & urubu & $x$ & & \\
\hline Sarcoramphus papa & urubu-rei & $x$ & & \\
\hline \multicolumn{5}{|l|}{ Pandionidae } \\
\hline Pandion haliaetus & águia-pescadora & $x$ & & VN \\
\hline \multicolumn{5}{|l|}{ Accipitridae } \\
\hline Leptodon cayanensis & gavião-gato & & $x$ & \\
\hline Chondrohierax uncinatus & caracoleiro & & $x$ & \\
\hline Elanoides forficatus & gavião-tesoura & $x$ & & \\
\hline Gampsonyx snainsonii & gaviãozinho & $x$ & & \\
\hline Elanus leucurus & gavião-peneira & $x$ & & \\
\hline Harpagus diodon & gavião-bombachinha & & $x$ & \\
\hline Circus buffoni & gavião-do-banhado & $x$ & & \\
\hline Accipiter superciliosus & tauató-passarinho & $x$ & & \\
\hline Ictinea plumbea & sovi & $x$ & & \\
\hline Busarellus nigricollis & gavião-belo & $x$ & & \\
\hline Rosthamus sociabilis & gavião-caramujeiro & $x$ & & \\
\hline
\end{tabular}




\begin{tabular}{|c|c|c|c|c|}
\hline Táxons & Nomes comúns & $\begin{array}{c}\text { UCs Ilha do } \\
\text { Bananal/ } \\
\text { Cantão }\end{array}$ & Wikiaves & Status \\
\hline Geranospiza caerulescens & gavião-pernilongo & $x$ & & \\
\hline Heterospizias meridionalis & gavião-caboclo & $x$ & & \\
\hline Urubitinga urubitinga & gavião-preto & $x$ & & \\
\hline Urubitinga coronata & Águia-cinzenta & $x$ & & $\mathrm{EN}^{\mathrm{A}, \mathrm{B}}$ \\
\hline Rupornis magnirostris & gavião-carijó & $x$ & & \\
\hline Geranoaetus albicaudatus & gavião-de-rabo-branco & $x$ & & \\
\hline Pseudastur albicollis & gavião-branco & $x$ & & \\
\hline Buteo nitidus & gavião-pedrês & $x$ & & \\
\hline Buteo brachyurus & gavião-de-cauda-curta & & $x$ & \\
\hline Buteo swainsoni & gavião-papa-gafanhoto & $x$ & & VN \\
\hline Buteo albonotatus & gavião-urubu & $x$ & & \\
\hline Harpia harpyja & uiraçu & $x$ & & VUA $N T^{B}$ \\
\hline Spizaetus tyrannus* & gavião-pega-macaco & $x$ & & \\
\hline Spizaetus melanoleucus & gavião-pato & & $x$ & \\
\hline Spizaetus ornatus & gavião-de-penacho & $x$ & & $N T^{B}$ \\
\hline \multicolumn{5}{|l|}{ Eurypigidae } \\
\hline Eurypyga helias* & pavãozinho-do-pará & $x$ & & \\
\hline \multicolumn{5}{|l|}{ Aramidae } \\
\hline Aramus guarauna & carão & $x$ & & \\
\hline \multicolumn{5}{|l|}{ Rallidae } \\
\hline Aramides ypecaha & saracuruçu & $x$ & & \\
\hline Aramides cajaneus & saracura-trêss-potes & $x$ & & \\
\hline Laterallus viridis & sanã-castanha & $x$ & & \\
\hline Laterallus exilis & sanã-do-capim & & & \\
\hline Mustelirallus albicollis & sanã-carijó & $x$ & & \\
\hline Pardirallus maculatus & saracura-carijó & & $x$ & \\
\hline Gallinula galeata & galinha-d'água & & & \\
\hline
\end{tabular}




\begin{tabular}{|c|c|c|c|c|}
\hline Táxons & Nomes comúns & $\begin{array}{c}\text { UCs Ilha do } \\
\text { Bananal/ } \\
\text { Cantão }\end{array}$ & Wikiaves & Status \\
\hline Porphyrio martinicus & frango-d’água-azul & $x$ & & \\
\hline Porphyrio flavirostris & frango-d'água-pequeno & $x$ & & \\
\hline \multicolumn{5}{|l|}{ Heliornitidae } \\
\hline Heliornis fulica & picaparra & $x$ & & \\
\hline \multicolumn{5}{|l|}{ Charadriidae } \\
\hline Vanellus cayanus & mexeriqueira & $x$ & & \\
\hline Vanellus chilensis & quero-quero & $x$ & & \\
\hline Pluvialis dominica & batuiruçu & $x$ & & VN \\
\hline Pluvialis squatarola & batuiruçu-de-axila-preta & $x$ & & VN \\
\hline Charadrius semipalmatus & batuíra-de-bando & $x$ & & VN \\
\hline Charadrius collaris & batuíra-de-coleira & $x$ & & \\
\hline \multicolumn{5}{|l|}{ Recurvirostridae } \\
\hline Himantopus melanurus & $\begin{array}{c}\text { pernilongo-de-costas- } \\
\text { brancas }\end{array}$ & & $x$ & \\
\hline \multicolumn{5}{|l|}{ Scolopacidae } \\
\hline Gallinago paraguaiae & narceja & $x$ & & \\
\hline Actitis macularius & maçarico-pintado & $x$ & & \\
\hline Tringa solitaria & maçarico-solitário & $x$ & & VN \\
\hline Tringa flavipes & maçarico-de-perna-amarela & $x$ & & VN \\
\hline Calidris fuscicollis & maçarico-de-sobre-branco & $x$ & & VN \\
\hline \multicolumn{5}{|l|}{ Jacanidae } \\
\hline Jacana jacana & jaçanã & $x$ & & \\
\hline \multicolumn{5}{|l|}{ Sternidae } \\
\hline Sternulla superciliaris & trinta-réis-pequeno & $x$ & & \\
\hline Phaetusa simplex & trinta-réis-grande & $x$ & & \\
\hline \multicolumn{5}{|l|}{ Rynchopidae } \\
\hline Rynchops niger & talha-mar & $x$ & & \\
\hline
\end{tabular}




\begin{tabular}{|c|c|c|c|c|}
\hline Táxons & Nomes comúns & $\begin{array}{c}\text { UCs Ilha do } \\
\text { Bananal/ } \\
\text { Cantão }\end{array}$ & Wikiaves & Status \\
\hline \multicolumn{5}{|l|}{ Columbidae } \\
\hline Columbina passerina & rolinha-cinzenta & $x$ & & \\
\hline Columbina minuta & rolinha-de-asa-canela & $x$ & & \\
\hline Columbina talpacoti & rolinha & $x$ & & \\
\hline Columbina squammata & fogo-apagou & $x$ & & \\
\hline Claravis pretiosa & pararu-azul & $x$ & & \\
\hline Uropelia campestris & rolinha-vaqueira & $x$ & & \\
\hline Patagioenas speciosa & pomba-trocal & $x$ & & \\
\hline Patagioenas picazuro & asa-branca & $x$ & & \\
\hline Patagioenas cayanensis & pomba-galega & $x$ & & \\
\hline Patagioenas subvinacea* & pomba-botafogo & $x$ & & \\
\hline Zenaida auriculata & avoante & $x$ & & \\
\hline Leptotila verreauxi & juriti-pupu & $x$ & & \\
\hline Leptotila rufaxilla & juriti-de-testa-branca & $x$ & & \\
\hline Geotrigon montana & pariri & $x$ & & \\
\hline \multicolumn{5}{|l|}{ Opisthocomidae } \\
\hline Opisthocomus hoazin* & cigana & $x$ & & \\
\hline \multicolumn{5}{|l|}{ Cuculidae } \\
\hline Coccycua minuta* & chincoã-pequeno & $x$ & & \\
\hline Piaya cayana & alma-de-gato & $x$ & & \\
\hline Coccyzus melacoryphus & papa-lagarta & & $x$ & \\
\hline Coccyzus euleri & papa-lagarta-de-euler & & $x$ & \\
\hline Crotophaga major & anu-coroca & $x$ & & \\
\hline Crotophaga ani & anu-preto & $x$ & & \\
\hline Guira guira & anu-branco & $x$ & & \\
\hline Tapera naevia & saci & $x$ & & \\
\hline Dromococcyx phasianellus & peixe-frito & $x$ & & \\
\hline
\end{tabular}




\begin{tabular}{|c|c|c|c|c|}
\hline Táxons & Nomes comúns & $\begin{array}{c}\text { UCs llha do } \\
\text { Bananal/ } \\
\text { Cantão }\end{array}$ & Wikiaves & Status \\
\hline Dromococcyx pavoninus & peixe-frito-pavonino & $x$ & & \\
\hline Neomorphus geoffroyi & jacu-estalo & & $x$ & VUA,B \\
\hline \multicolumn{5}{|l|}{ Tytonidae } \\
\hline Tyto furcata & suindara & $x$ & & \\
\hline \multicolumn{5}{|l|}{ Strigidae } \\
\hline Megascops choliba & corujinha-do-mato & $x$ & & \\
\hline Megascops watsonii & corujinha-orelhuda & $x$ & & \\
\hline Megascops usta & corujinha-relógio & & $x$ & ENA \\
\hline Lophostrix cristata & coruja-de-crista & $x$ & & \\
\hline Pulsatrix perspicillata & murucututu & $x$ & & \\
\hline Bubo viginianus & jucurutu & $x$ & & \\
\hline Strix huhula & coruja-preta & $x$ & & \\
\hline Glaucidium brasilianum & caburé & $x$ & & \\
\hline Athene cunicularia & coruja-buraqueira & $x$ & & \\
\hline \multicolumn{5}{|l|}{ Nyctibiidae } \\
\hline Nyctibius grandis & urutau-grande & & $x$ & \\
\hline Nyctibius griseus & urutau & $x$ & & \\
\hline \multicolumn{5}{|l|}{ Caprimulgidae } \\
\hline Antrostomus rufus & joão-corta-pau & $x$ & & \\
\hline Lurocalis semitorquatus & tuju & $x$ & & \\
\hline Nyctiprogne leucopyga & bacurau-de-cauda-barrada & $x$ & & \\
\hline Nyctidromus nigrescens & bacurau-de-lajeado & & $x$ & ENA \\
\hline Nyctidromus albicollis & bacurau & $x$ & & \\
\hline Hydropsalis parvula & bacurau-chintã & $x$ & & \\
\hline Hydropsalis maculicaudus & bacurau-de-rabo-maculado & $x$ & & \\
\hline Hydropsalis climacocerca & acurana & $x$ & & ENA \\
\hline
\end{tabular}




\begin{tabular}{|c|c|c|c|c|}
\hline Táxons & Nomes comúns & $\begin{array}{c}\text { UCs Ilha do } \\
\text { Bananal/ } \\
\text { Cantão }\end{array}$ & Wikiaves & Status \\
\hline Hydropsalis torquata & bacurau-tesoura & $x$ & & \\
\hline Nannochordeiles pusillus & bacurauzinho & & $x$ & \\
\hline Podager nacunda & corucão & & $x$ & \\
\hline Chordeiles rupestres & bacurau-da-praia & $x$ & & \\
\hline Chordeiles acutipennis & bacurau-de-asa-fina & $x$ & & \\
\hline \multicolumn{5}{|l|}{ Apodidae } \\
\hline Cypseloides senex & taperuçu-velho & $x$ & & \\
\hline Streptoprocne zonaris & taperuçu-de-coleira-branca & & $x$ & \\
\hline Chaetura spinicaudus & andorinhão-de-sobre-branco & $x$ & & \\
\hline Chaetura meridionalis & andorinhão-do-temporal & $x$ & & \\
\hline Tachornis squamata & andorinhão-do-buriti & $x$ & & \\
\hline Panyptila cayennensis & andorinhão-estofador & $x$ & & \\
\hline \multicolumn{5}{|l|}{ Trochilidae } \\
\hline Glaucis hirsutus & balança-rabo-de-bico-torto & $x$ & & \\
\hline Phaethornis maranhaoensis & rabo-branco-do-maranhão & $x$ & & \\
\hline Phaethornis nattereri & besourão-de-sobre-amarelo & $x$ & & \\
\hline Phaethornis ruber & rabo-branco-rubro & $x$ & & \\
\hline Phaethornis pretrei & rabo-branco-acanelado & $x$ & & \\
\hline Eupetomena macroura & beija-flor-tesoura & $x$ & & \\
\hline Anthracothorax nigricollis & beija-flor-de-veste-preta & $x$ & & \\
\hline Chrysolampis mosquitus & beija-flor-vermelho & $x$ & & \\
\hline Lophornis gouldii & topetinho-do-brasil-central & $x$ & & VUA,B \\
\hline Lophornis magnificus & topetinho-vermelho & $x$ & & \\
\hline Chlorestes notata & beija-flor-de-garganta-azul & & $x$ & \\
\hline
\end{tabular}




\begin{tabular}{|c|c|c|c|c|}
\hline Táxons & Nomes comúns & $\begin{array}{c}\text { UCs Ilha do } \\
\text { Bananal/ } \\
\text { Cantão }\end{array}$ & Wikiaves & Status \\
\hline Chlorostibon mellisugus* & esmeralda-de-cauda-azul & $x$ & & \\
\hline Thalurania furcata & beija-flor-tesoura-verde & $x$ & & \\
\hline Hylocharis cyanus & beija-flor-roxo & $x$ & & \\
\hline Polytimus guainumbi & beija-flor-de-bico-curvo & $x$ & & \\
\hline Amazilia versicolor & beija-flor-de-banda-branca & $x$ & & \\
\hline Amazilia fimbriata & beija-flor-de-garganta-verde & $x$ & & \\
\hline Heliomaster longirostris* & bico-reto-cinzento & $x$ & & \\
\hline Heliomaster furcifer & bico-reto-azul & & $x$ & \\
\hline \multicolumn{5}{|l|}{ Trogonidae } \\
\hline Trogon melanurus* & surucuá-de-cauda-preta & $x$ & & \\
\hline Trogon viridis* & surucuá-de-barriga-amarela & $x$ & & \\
\hline Trogon curucui & $\begin{array}{l}\text { surucuá-de-barriga- } \\
\text { vermelha }\end{array}$ & $x$ & & \\
\hline \multicolumn{5}{|l|}{ Alcedinidae } \\
\hline Megaceryle torquata & martim-pescador-grande & $x$ & & \\
\hline Chloroceryle amazona & martim-pescador-verde & $x$ & & \\
\hline Cloroceryle aenea & martim-pescador-miúdo & $x$ & & \\
\hline Chloroceryle americana & martim-pescador-pequeno & $x$ & & \\
\hline Chloroceryle inda & martim-pescador-da-mata & $x$ & & \\
\hline \multicolumn{5}{|l|}{ Momotidae } \\
\hline Momotus momota & udu & $x$ & & \\
\hline \multicolumn{5}{|l|}{ Galbulidae } \\
\hline Brachygalba lugubris & ariramba-preta & $x$ & & \\
\hline Galbula ruficauda & ariramba & $x$ & & \\
\hline Bucconidae & & & & \\
\hline
\end{tabular}




\begin{tabular}{|c|c|c|c|c|}
\hline Táxons & Nomes comúns & $\begin{array}{c}\text { UCs Ilha do } \\
\text { Bananal/ } \\
\text { Cantão }\end{array}$ & Wikiaves & Status \\
\hline Notharchus tectus* & macuru-pintado & $x$ & & \\
\hline Bucco tamatia* & rapazinho-carijó & $x$ & & ENA \\
\hline Nystalus chacuru & joão-bobo & $x$ & & \\
\hline Nystalus maculatus & rapazinho-dos-velhos & $x$ & & \\
\hline Monasa nigrifrons & chora-chuva-preto & $x$ & & \\
\hline Chelidoptera tenebrosa & urubuzinho & $x$ & & \\
\hline \multicolumn{5}{|l|}{ Ramphastidae } \\
\hline Ramphastos toco & tucanuçu & $x$ & & \\
\hline Ramphastos tucanus & tucano-de-papo-branco & & $x$ & $\begin{array}{l}\text { NT'B } \\
\text { ENA }\end{array}$ \\
\hline Ramphastos vitellinus & tucano-de-bico-preto & $x$ & & \\
\hline Pteroglossus inscriptus* & araçari-de-bico-riscado & $x$ & & ENA \\
\hline Pteroglossus aracari & araçari-de-bico-branco & $x$ & & \\
\hline Pteroglossus castanotis & araçari-castanho & $x$ & & \\
\hline \multicolumn{5}{|l|}{ Picidae } \\
\hline Picumnus albosquamatus & picapauzinho-escamoso & $x$ & & \\
\hline Melanerpes candidus & pica-pau-branco & $x$ & & \\
\hline Melanerpes cruentatus* & benedito-de-testa-vermelha & $x$ & & \\
\hline Veniliornis affinis & picapauzinho-avermelhado & $x$ & & \\
\hline Veniliornis passerinus & pica-pau-pequeno & $x$ & & \\
\hline Piculus leucolaemus & $\begin{array}{c}\text { pica-pau-de-garganta- } \\
\text { branca }\end{array}$ & & $x$ & \\
\hline Piculus flavigula & pica-pau-bufador & $x$ & & \\
\hline Piculus laemostictus & $\begin{array}{c}\text { pica-pau-de-garganta- } \\
\text { pintada }\end{array}$ & & $x$ & ENA \\
\hline Piculus chrysochloros & pica-pau-dourado-escuro & $x$ & & \\
\hline Colaptes melanochloros & pica-pau-verde-barrado & $x$ & & \\
\hline
\end{tabular}




\begin{tabular}{|c|c|c|c|c|}
\hline Táxons & Nomes comúns & $\begin{array}{c}\text { UCs Ilha do } \\
\text { Bananal/ } \\
\text { Cantão }\end{array}$ & Wikiaves & Status \\
\hline Colaptes campestris & pica-pau-do-campo & $x$ & & \\
\hline Celeus torquatus & pica-pau-de-coleira & $x$ & & \\
\hline Celeus ochraceus & pica-pau-ocráceo & & $x$ & \\
\hline Celeus flavescens & pica-pau-de-cabeça-amarela & $x$ & & \\
\hline Celeus elegans & pica-pau-chocolate & $x$ & & \\
\hline Celeus flavus & pica-pau-amarelo & $x$ & & \\
\hline Celeus obrieni & pica-pau-do-parnaíba & $x$ & & VUA,B \\
\hline Dryocopus lineatus & pica-pau-de-banda-branca & $x$ & & \\
\hline Campephilus rubricollis* & $\begin{array}{c}\text { pica-pau-de-barriga- } \\
\text { vermelha }\end{array}$ & $x$ & & ENA \\
\hline Campephilus melanoleucos & $\begin{array}{l}\text { pica-pau-de-topete- } \\
\text { vermelho }\end{array}$ & $x$ & & \\
\hline \multicolumn{5}{|l|}{ Cariamidae } \\
\hline Cariama cristata & seriema & $x$ & & \\
\hline \multicolumn{5}{|l|}{ Falconidae } \\
\hline Daptrius ater* & gavião-de-anta & $x$ & & \\
\hline Ibycter americanus & cancão & $x$ & & \\
\hline Caracara plancus & carcará & $x$ & & \\
\hline Mivalgo chimachima & carrapateiro & $x$ & & \\
\hline Herpetotheres cachinnans & acauã & $x$ & & \\
\hline Micrastur ruficollis & falcão-caburé & & $x$ & \\
\hline Falco sparverius & quiriquiri & $x$ & & \\
\hline Falco rufigularis & cauré & $x$ & & \\
\hline Falco femoralis & falcão-de-coleira & $x$ & & \\
\hline Falco peregrinus & falcão-peregrino & $x$ & & VN \\
\hline \multicolumn{5}{|l|}{ Psittacidae } \\
\hline Ara ararauna & arara-canindé & $x$ & & \\
\hline Ara severus & maracanã-guaçu & & $x$ & ENA \\
\hline
\end{tabular}




\begin{tabular}{|c|c|c|c|c|}
\hline Táxons & Nomes comúns & $\begin{array}{c}\text { UCs llha do } \\
\text { Bananal/ } \\
\text { Cantão }\end{array}$ & Wikiaves & Status \\
\hline Orthopsittaca manilata & maracanã-do-buriti & $x$ & & \\
\hline Primolius maracana & maracanã & $x$ & & NTB \\
\hline Primolius auricollis & maracanã-de-colar & $x$ & & \\
\hline Diopsittaca nobilis & maracanã-pequena & $x$ & & \\
\hline Psittacara leucophthamus & periquitão & $x$ & & \\
\hline Aratinga jandaya & jandaia & & $x$ & \\
\hline Eupsittula aurea & periquito-rei & $x$ & & \\
\hline Pyrrhura amazonum & tiriba-de-hellmayr & & $x$ & $\mathrm{EN}^{\mathrm{B}}$ \\
\hline Brotogeris chiriri & $\begin{array}{l}\text { periquito-de-encontro- } \\
\text { amarelo }\end{array}$ & $x$ & & \\
\hline Alipiopsitta xanthops & papagaio-galego & $x$ & & $N T^{B}, E N C$ \\
\hline Piomus menstruus* & maitaca-de-cabeça-azul & $x$ & & \\
\hline Pionus maximiliani & maitaca & & $x$ & \\
\hline Amazona amazonica & curica & $x$ & & \\
\hline Amazona aestiva & papagaio & $x$ & & \\
\hline \multicolumn{5}{|l|}{ Thamnophilidae } \\
\hline Myrmotherula multostriata & $\begin{array}{c}\text { choquinha-estriada-da- } \\
\text { amazônia }\end{array}$ & $x$ & & \\
\hline Myrmotherula axillaris & choquinha-de-flanco-branco & $x$ & & \\
\hline Formicivora grisea & papa-formiga-pardo & $x$ & & \\
\hline Formicivora rufa & papa-formiga-vermelho & $x$ & & \\
\hline Dysithamnus mentalis & choquinha-lisa & $x$ & & \\
\hline Herpsilochmus atricapillus & chorozinho-de-chapéu-preto & $x$ & & \\
\hline Herpsilochmus longirostris & $\begin{array}{l}\text { chorozinho-de-bico- } \\
\text { comprido }\end{array}$ & $x$ & & ENC \\
\hline Sakesphorus luctuosus* & choca-d'água & $x$ & & ENA \\
\hline Thamnophilus doliatus & choca-barrada & $x$ & & \\
\hline Thamnophilus pelzelni & choca-do-planalto & $x$ & & \\
\hline
\end{tabular}




\begin{tabular}{|c|c|c|c|c|}
\hline Táxons & Nomes comúns & $\begin{array}{c}\text { UCs Ilha do } \\
\text { Bananal/ } \\
\text { Cantão }\end{array}$ & Wikiaves & Status \\
\hline Thamnophilus amazonicus* & choca-canela & $x$ & & ENA \\
\hline Taraba major & choró-boi & $x$ & & \\
\hline Hypocnemoides maculicauda* & solta-asa & $x$ & & ENA \\
\hline Cercomacra ferdinandi & chororó-de-goiás & $x$ & & $\begin{array}{l}\text { VUA,B } \\
\text { ENC }\end{array}$ \\
\hline \multicolumn{5}{|l|}{ Melanopareiidae } \\
\hline Melanopareia torquata & tapaculo-de-colarinho & $x$ & & ENC \\
\hline \multicolumn{5}{|l|}{ Dendrocolaptidae } \\
\hline Dendrocincla fuliginosa* & arapaçu-pardo & $x$ & & \\
\hline Sittasomus griseicapillus & arapaçu-verde & $x$ & & \\
\hline Xiphorhynchus obsoletus & arapaçu-riscado & $x$ & & ENA \\
\hline Xiphorhynchus guttatus & $\begin{array}{c}\text { arapaçu-de-garganta- } \\
\text { amarela }\end{array}$ & $x$ & & ENA \\
\hline Xiphorhynchus guttatoides & arapaçu-de-lafresnaye & & $x$ & \\
\hline Dendroplex picus & arapaçu-de-bico-branco & $x$ & & \\
\hline Lepidocolaptes angustirostris & arapaçu-de-cerrado & $x$ & & \\
\hline Nasica longirostris* & arapaçu-de-bico-comprido & $x$ & & ENA \\
\hline Dendrocolaptes certhia* & arapaçu-barrado & $x$ & & ENA \\
\hline Dendrocolaptes retentus & arapaçu-barrado-do-xingu & & $x$ & $\begin{array}{l}\text { VUA } \\
\text { ENA }\end{array}$ \\
\hline \multicolumn{5}{|l|}{ Xenopidae } \\
\hline Xenops minutus & bico-virado-miúdo & $x$ & & \\
\hline Xenops rutilans & bico-virado-carijô & & $x$ & \\
\hline \multicolumn{5}{|l|}{ Furnariidae } \\
\hline Berlepschia rikeri & limpa-folha-do-buriti & & $x$ & \\
\hline Furnarius figulus & casaca-de-couro-da-lama & $x$ & & \\
\hline Furnarius leucopus & casaca-de-couro-amarelo & $x$ & & \\
\hline
\end{tabular}




\begin{tabular}{|c|c|c|c|c|}
\hline Táxons & Nomes comúns & $\begin{array}{c}\text { UCs Ilha do } \\
\text { Bananal/ } \\
\text { Cantão } \\
\end{array}$ & Wikiaves & Status \\
\hline Furnarius rufus & joão-de-barro & $x$ & & \\
\hline Phacellodomus ruber & graveteiro & $x$ & & \\
\hline Certhiaxis cinnamomeus & curutié & $x$ & & \\
\hline Certhiaxis sp. & "curutié-do-cantão" & $x$ & & \\
\hline Synallaxis frontalis & petrim & & $x$ & \\
\hline Synallaxis albescens & ui-pí & $x$ & & \\
\hline Synallaxis simoni & joão-do-araguaia & $x$ & & ENC \\
\hline Cranioleuca vulpina & arredio-do-rio & $x$ & & \\
\hline \multicolumn{5}{|l|}{ Pipridae } \\
\hline Neopelma pallescens & fruxu-do-cerradão & $\mathrm{x}$ & & \\
\hline Tyranneutes stolzmanni* & uirapuruzinho & $x$ & & ENA \\
\hline Pipra fasciicauda & uirapuru-laranja & $x$ & & \\
\hline Ceratopipra rubrocapilla* & cabeça-encarnada & $x$ & & \\
\hline Manacus manacus & rendeira & $x$ & & \\
\hline Heterocercus linteatus* & coroa-de-fogo & $x$ & & ENA \\
\hline Machaeropterus pyrocephalus* & uirapuru-cigarra & $x$ & & ENA \\
\hline Xenopipo atronitens & pretinho & $x$ & & ENA \\
\hline $\begin{array}{l}\text { Chiroxiphia pareola* } \\
\text { Antilophia galeata } \\
\text { Onychorhynchidae }\end{array}$ & $\begin{array}{c}\text { tangará-príncipe } \\
\text { soldadinho }\end{array}$ & $x$ & $x$ & \\
\hline Terenotriccus erythrurus & papa-moscas-uirapuru & $x$ & & \\
\hline Myiobius atricaudus & $\begin{array}{c}\text { assanhadinho-de-cauda- } \\
\text { preta }\end{array}$ & $x$ & & \\
\hline \multicolumn{5}{|l|}{ Tityridae } \\
\hline Schiffornis turdina & flautim-marrom & & $x$ & \\
\hline Tityra inquisitor & $\begin{array}{l}\text { anambé-branco-de- } \\
\text { bochecha-parda }\end{array}$ & $x$ & & \\
\hline Tityra cayana & $\begin{array}{c}\text { anambé-branco-de-rabo- } \\
\text { preto }\end{array}$ & $x$ & & \\
\hline
\end{tabular}




\begin{tabular}{|c|c|c|c|c|}
\hline Táxons & Nomes comúns & $\begin{array}{c}\text { UCs Ilha do } \\
\text { Bananal/ } \\
\text { Cantão }\end{array}$ & Wikiaves & Status \\
\hline Tityra semifasciata* & $\begin{array}{c}\text { anambé-branco-de-m.scara- } \\
\text { negra }\end{array}$ & $x$ & & \\
\hline Pachyramphus polychopterus & caneleiro-preto & $x$ & & \\
\hline Pachyramphus marginatus & caneleiro-bordado & & $x$ & \\
\hline Xenopsaris albinucha & tijerila & $x$ & & \\
\hline \multicolumn{5}{|l|}{ Cotingidae } \\
\hline Querula purpurata* & anambé-una & $x$ & & \\
\hline Lipaugus vociferans* & cricrió & $x$ & & \\
\hline Gymnoderus foetidus * & anambé-pombo & $x$ & & ENA \\
\hline \multicolumn{5}{|l|}{ Platyrinchidae } \\
\hline Platyrinchus mystaceus & patinho & $x$ & & \\
\hline Platyrinchus platyrhynchos & patinho-de-coroa-branca & $\mathrm{x}$ & & \\
\hline \multicolumn{5}{|l|}{ Rhynchocyclidae } \\
\hline Mionectes oleagineus & abre-asa & & $x$ & \\
\hline Leptopogon amaurocephalus & cabeçudo & $x$ & & \\
\hline Corythopis torquatus* & estalador-do-norte & $x$ & & ENA \\
\hline Tolmomyias sulphurescens & bico-chato-de-orelha-preta & $x$ & & \\
\hline Tolmomyias assimilis & bico-chato-de-orelha-preta & $x$ & & \\
\hline Tolmomyias poliocephalus & bico-chato-de-cabe.a-cinza & $x$ & & \\
\hline Tolmomyias flaviventris & bico-chato-amarelo & $x$ & & \\
\hline Todirostrum maculatum & ferreirinho-estriado & $x$ & & ENA \\
\hline Todirostrum cinereum & ferreirinho-relógio & $x$ & & \\
\hline Poecilotriccus fumifrons & ferreirinho-de-testa-parda & $x$ & & \\
\hline Poecilotriccus latirostris & ferreirinho-de-cara-parda & $x$ & & \\
\hline
\end{tabular}




\begin{tabular}{|c|c|c|c|c|}
\hline Táxons & Nomes comúns & $\begin{array}{c}\text { UCs Ilha do } \\
\text { Bananal/ } \\
\text { Cantão }\end{array}$ & Wikiaves & Status \\
\hline Myiornis ecaudatus & caçula & $x$ & & \\
\hline Hemitriccus minor & maria-sebinha & $x$ & & \\
\hline Hemitriccus striaticollis* & sebinho-rajado-amarelo & $x$ & & \\
\hline Hemitriccus minimus* & maria-mirim & $x$ & & ENA \\
\hline \multicolumn{5}{|l|}{ Tyrannidae } \\
\hline Inezia subflava & amarelinho & $x$ & & \\
\hline Ornithion inerme* & poiaeiro-de-sobrancelha & $x$ & & \\
\hline Camptostoma obsoletum & risadinha & $x$ & & \\
\hline Elaenia flavogaster & $\begin{array}{c}\text { guaracava-de-barriga- } \\
\text { amarela }\end{array}$ & $x$ & & \\
\hline Elaenia spectabilis & guaracava-grande & $x$ & & \\
\hline Elaenia parvirostris & tuque-pium & $x$ & & \\
\hline Elaenia cristata & $\begin{array}{c}\text { guaracava-de-topete- } \\
\text { uniforme }\end{array}$ & $x$ & & \\
\hline Elaenia chiriquensis & chibum & $x$ & & \\
\hline Suiriri suiriri & suiriri-cinzento & $x$ & & \\
\hline Myiopagis gaimardii & maria-pechim & $x$ & & \\
\hline Myiopagis viridicata & $\begin{array}{c}\text { guaracava-de-crista- } \\
\text { alaranjada }\end{array}$ & $x$ & & \\
\hline Tyrannulus elatus & maria-te-viu & $x$ & & \\
\hline Capsiempis flaveola & marianinha-amarela & & $x$ & \\
\hline Phaeomyias murina & bagageiro & $x$ & & \\
\hline Phyllomyias fasciatus & piolhinho & & $x$ & \\
\hline Serpophaga hypoleuca & alegrinho-do-rio & $x$ & & $\begin{array}{l}\text { VUA } \\
\text { ENA }\end{array}$ \\
\hline Attila cinnamomeus & tinguaçu-ferrugem & $x$ & & \\
\hline Attila spadiceus & capitão-de-saíra-amarelo & & $x$ & \\
\hline Legatus leucophaius & bem-te-vi-pirata & $x$ & & \\
\hline
\end{tabular}




\begin{tabular}{|c|c|c|c|c|}
\hline Táxons & Nomes comúns & $\begin{array}{c}\text { UCs Ilha do } \\
\text { Bananal/ } \\
\text { Cantão }\end{array}$ & Wikiaves & Status \\
\hline Ramphotrigon ruficauda & $\begin{array}{l}\text { bico-chato-de-rabo- } \\
\text { vermelho }\end{array}$ & $x$ & & \\
\hline Myiarchus tuberculifer ${ }^{1}$ & maria-cavaleira-pequena & $x$ & & \\
\hline Myiarchus swainsoni & irré & $x$ & & \\
\hline Myiarchus ferox & maria-cavaleira & $x$ & & \\
\hline Myiarchus tyrannulus & $\begin{array}{l}\text { maria-cavaleira-de-rabo- } \\
\text { enferrujado }\end{array}$ & $x$ & & \\
\hline Sirystes sibilator & gritador & $x$ & & \\
\hline Rhytipterna simplex & vissiá & $x$ & & \\
\hline Casiornis rufus & maria-ferrugem & $x$ & & \\
\hline Casiornis fuscus & caneleiro-enxofre & $x$ & & \\
\hline Pitangus sulphuratus & bem-te-vi & $x$ & & \\
\hline Philohydor lictor & bentevizinho-do-brejo & $x$ & & \\
\hline Myiodynastes maculatus & bem-te-vi-rajado & $x$ & & \\
\hline Tyrannopsis sulphurea & suiriri-de-garganta-rajada & & $x$ & \\
\hline Megarynchus pitanga & neinei & $x$ & & \\
\hline Myiozetetes cayanensis & $\begin{array}{l}\text { bentevizinho-de-asa- } \\
\text { ferrugínea }\end{array}$ & $x$ & & \\
\hline Myiozetetes similis & $\begin{array}{c}\text { bentevizinho-de-penacho- } \\
\text { vermelho }\end{array}$ & $x$ & & \\
\hline Tyrannus albogularis & suiriri-de-garganta-branca & $x$ & & \\
\hline Tyrannus melancholicus & suiriri & $x$ & & \\
\hline Tyrannus savanna & tesourinha & $x$ & & \\
\hline $\begin{array}{l}\text { Griseotyranus } \\
\text { aurantioatrocristatus }\end{array}$ & peitica-de-chapéu-preto & $x$ & & \\
\hline Empidonomus varius & peitica & $x$ & & \\
\hline Colonia colonus & viuvinha & $x$ & & \\
\hline Myiophobus fasciatus & filipe & $x$ & & \\
\hline Fluvicola albiventer & lavadeira-de-cara-branca & $x$ & & \\
\hline
\end{tabular}




\begin{tabular}{|c|c|c|c|c|}
\hline Táxons & Nomes comúns & $\begin{array}{c}\text { UCs Ilha do } \\
\text { Bananal/ } \\
\text { Cantão }\end{array}$ & Wikiaves & Status \\
\hline Arundinicola leucocephala & freirinha & $x$ & & \\
\hline Cnemotriccus fuscatus & guaracavuçu & $x$ & & \\
\hline Lathrotriccus euleri & enferrujado & $x$ & & \\
\hline Knipolegus poecilocercus & pretinho-do-igapó & $x$ & & ENA \\
\hline Knipolegus orenocencis* & maria-preta-ribeirinha & $x$ & & ENA \\
\hline Satrapa icterophrys & suiriri-pequeno & $x$ & & \\
\hline Xolmis cinereus & primavera & $x$ & & \\
\hline Xolmis velatus & noivinha-branca & & $x$ & \\
\hline Vireonidae & & $x$ & & \\
\hline Cyclarhis gujanensis & pitiguari & $x$ & & \\
\hline Hylophilus pectoralis* & vite-vite-de-cabe.a-cinza & $x$ & & ENA \\
\hline Hylophilus semicinereus & verdinho-da-várzea & $x$ & & ENA \\
\hline Vireo chivi & juruviara & $x$ & & VN \\
\hline \multicolumn{5}{|l|}{ Corvidae } \\
\hline Cyanocorax cristatellus & gralha-do-campo & & $x$ & \\
\hline Cyanocorax cyanopogon & gralha-cancã & $x$ & & \\
\hline \multicolumn{5}{|l|}{ Hirundinidae } \\
\hline Pygochelidon melanoleuca & andorinha-de-coleira & & $x$ & \\
\hline Stelgidopteryx ruficollis & andorinha-serradora & $x$ & & \\
\hline Progne tapera & andorinha-do-campo & $x$ & & \\
\hline Progne subis & andorinha-azul & $x$ & & VN \\
\hline Progne chalybea & andorinha-grande & $x$ & & \\
\hline Tachycineta albiventer & andorinha-do-rio & $x$ & & \\
\hline Riparia riparia & andorinha-do-barranco & $x$ & & \\
\hline Hirundo rustica & andorinha-de-bando & $x$ & & VN \\
\hline
\end{tabular}




\begin{tabular}{|c|c|c|c|c|}
\hline Táxons & Nomes comúns & $\begin{array}{c}\text { UCs Ilha do } \\
\text { Bananal/ } \\
\text { Cantão }\end{array}$ & Wikiaves & Status \\
\hline \multicolumn{5}{|l|}{ Troglodytidae } \\
\hline Troglodytes musculus & corruíra & $x$ & & \\
\hline Pheugopedius genibarbis & garrinchão-pai-avô & $x$ & & \\
\hline Cantorchilus leucotis & $\begin{array}{c}\text { garrinchão-de-barriga- } \\
\text { vermelha }\end{array}$ & $x$ & & \\
\hline \multicolumn{5}{|l|}{ Donacobiidae } \\
\hline Donacobius atricapilla & japacanim & $x$ & & \\
\hline \multicolumn{5}{|l|}{ Polioptilidae } \\
\hline Polioptila dumicola & balança-rabo-de-másscara & $x$ & & \\
\hline \multicolumn{5}{|l|}{ Turdinae } \\
\hline Turdus leucomelas & sabiá-branco & $x$ & & \\
\hline Turdus fumigatus* & sabiá-da-mata & $x$ & & \\
\hline Turdus amaurochalinus & sabiá-poca & $x$ & & \\
\hline Turdus subalaris & sabiá-ferreiro & & $x$ & \\
\hline Turdus albicollis & sabiá-coleira & $x$ & & \\
\hline \multicolumn{5}{|l|}{ Mimidae } \\
\hline Mimus saturninus & sabiá-do-campo & $x$ & & \\
\hline \multicolumn{5}{|l|}{ Motacilidae } \\
\hline Anthus lutescens & caminheiro-zumbidor & $x$ & & \\
\hline \multicolumn{5}{|l|}{ Passerellidae } \\
\hline Zonotrichia capensis & tico-tico & & $x$ & \\
\hline Ammodramus humeralis & tico-tico-do-campo & $x$ & & \\
\hline Ammodramus aurifrons & cigarrinha-do-campo & $x$ & & \\
\hline Arremon taciturnus & tico-tico-de-bico-preto & $x$ & & \\
\hline
\end{tabular}




\begin{tabular}{|c|c|c|c|c|}
\hline Táxons & Nomes comúns & $\begin{array}{c}\text { UCs llha do } \\
\text { Bananal/ } \\
\text { Cantão }\end{array}$ & Wikiaves & Status \\
\hline \multicolumn{5}{|l|}{ Parulidae } \\
\hline Basileuterus culicivorus & pula-pula & $x$ & & \\
\hline Myiothlypis flaveola & canário-do-mato & $x$ & & \\
\hline \multicolumn{5}{|l|}{ Icteridae } \\
\hline Psarocolius decumanus & japu & $x$ & & \\
\hline Procacicus solitarius & iraúna-de-bico-branco & $x$ & & \\
\hline Cacicus cela* & xexéu & $x$ & & \\
\hline Icterius cayanensis & inhapim & $x$ & & \\
\hline Icterius jamacaii & corrupião & $x$ & & \\
\hline Icterus croconotus & joão-pinto & & $x$ & \\
\hline Gnorimopsar chopi & pássaro-preto & $x$ & & \\
\hline Chrysomus ruficapillus & garibaldi & & $x$ & \\
\hline Molothrus rufoaxillaris & chupim-azeviche & & $x$ & \\
\hline Molothrus oryzivorus & iraúna-grande & $x$ & & \\
\hline Molothrus bonariensis & chupim & $x$ & & \\
\hline Sturnella militaris & polícia-inglesa-do-norte & $x$ & & \\
\hline Sturnella superciliaris & polícia-inglesa-do-sul & & $x$ & \\
\hline \multicolumn{5}{|l|}{ Thraupidae } \\
\hline Porphyrospiza caerulescens & campainha-azul & & $x$ & $N T^{B}$ \\
\hline Neothraupis fasciata & cigarra-do-campo & & $x$ & $\begin{array}{l}\text { NTB } \\
\text { ENC }\end{array}$ \\
\hline Cissopis leverianus & tietinga & $x$ & & \\
\hline Schistochlamys melanopis & sanhaço-de-coleira & $x$ & & \\
\hline Schistochlamys ruficapillus & bico-de-veludo & $x$ & & \\
\hline Paroaria baeri & cardeal-do-araguaia & $x$ & & ENC \\
\hline Paroaria gularis & cardeal-da-amazônia & $x$ & & \\
\hline Tangara mexicana & saíra-de-bando & & $x$ & ENA \\
\hline
\end{tabular}




\begin{tabular}{|c|c|c|c|c|}
\hline Táxons & Nomes comúns & $\begin{array}{c}\text { UCs Ilha do } \\
\text { Bananal/ } \\
\text { Cantão }\end{array}$ & Wikiaves & Status \\
\hline Tangara sayaca & sanhaço-cinzento & $x$ & & \\
\hline Tangara palmarum & sanhaço-do-coqueiro & $x$ & & \\
\hline Tangara cyanicollis & saíra-de-cabeça-azul & & $x$ & ENA \\
\hline Tangara cayana & saíra-amarela & $x$ & & \\
\hline Nemosia pileata & saíra-de-chapéu-preto & $x$ & & \\
\hline Compsothraupis loricata & tié-caburé & $x$ & & \\
\hline Conirostrum speciosum & figuinha-de-rabo-castanho & $x$ & & \\
\hline Sicalis flaveola & canário-da-terra & & $x$ & \\
\hline Sicalis columbiana & canário-do-amazonas & $x$ & & \\
\hline Hemithraupis flavicollis & saíra-galega & & $x$ & \\
\hline Hemithraupis guira & saíra-de-papo-preto & $x$ & & \\
\hline Volatinia jacarina & tiziu & $x$ & & \\
\hline Eucometis penicillata & pipira-da-taoca & $x$ & & \\
\hline Coryphospingus pileatus & tico-tico-rei-cinza & $x$ & & \\
\hline Lanio luctuosus* & tem-tem-de-dragona-branca & $x$ & & \\
\hline Lanio cristatus & tiê-galo & $x$ & & \\
\hline Tachyphonus rufus & pipira-preta & $x$ & & \\
\hline Ramphocelus carbo & pipira-vermelha & $x$ & & \\
\hline Charitospiza eucosma & mineirinho & $x$ & & $\mathrm{NT}^{\mathrm{B}}, \mathrm{ENC}$ \\
\hline Tersina viridis & saí-andorinha & $x$ & & \\
\hline Cyanerpes cyaneus & saíra-beija-flor & $x$ & & \\
\hline Dacnis flaviventer & saí-amarela & & $x$ & ENA \\
\hline Dacnis cayana & saí-azul & $x$ & & \\
\hline Coereba flaveola & cambacica & $x$ & & \\
\hline
\end{tabular}




\begin{tabular}{|c|c|c|c|c|}
\hline Táxons & Nomes comúns & $\begin{array}{c}\text { UCs Ilha do } \\
\text { Bananal/ } \\
\text { Cantão }\end{array}$ & Wikiaves & Status \\
\hline Sporophila lineola & bigodinho & $x$ & & \\
\hline Sporophila schistacea* & cigarrinha-do-norte & $x$ & & \\
\hline Sporophila plumbea & patativa & $x$ & & \\
\hline Sporophila americana & coleiro-do-norte & & $x$ & ENA \\
\hline Sporophila collaris & coleiro-do-brejo & $x$ & & \\
\hline Sporophila nigricollis & baiano & $x$ & & \\
\hline Sporophila caerulescens & coleirinho & $x$ & & \\
\hline Sporophila leucoptera & chorão & & $x$ & ENA \\
\hline Sporophila bouvreuil & caboclinho & $\mathrm{x}$ & & \\
\hline Sporophila castaneiventris & $\begin{array}{c}\text { caboclinho-de-peito- } \\
\text { castanho }\end{array}$ & $\mathrm{x}$ & & ENA \\
\hline Sporophila angolensis & curió & $x$ & & \\
\hline Emberizoides herbicola & canário-do-campo & $x$ & & \\
\hline Saltatricula atricollis & batuqueiro & $x$ & & ENC \\
\hline Saltator maximus & tempera-viola & $x$ & & \\
\hline Saltator coerulescens & sabiá-gongá & $x$ & & \\
\hline Thlypopsis sordida & saí-canário & $x$ & & \\
\hline Cypsnagra hirundinacea & bandoleta & $x$ & & \\
\hline \multicolumn{5}{|l|}{ Cardinalidae } \\
\hline Piranga flava & sanhaço-de-fogo & $x$ & & \\
\hline Granatelus pelzelni & polícia-do-mato & $x$ & & ENA \\
\hline Cyanoloxia rothschildii & azulão-da-amazônia & & & \\
\hline \multicolumn{5}{|l|}{ Fringilidae } \\
\hline Euphonia chlorotica & fim-fim & $x$ & & \\
\hline Euphonia violacea & gaturamo & $x$ & & \\
\hline \multicolumn{5}{|l|}{ Passeridae } \\
\hline Passer domesticus & pardal & $x$ & & \\
\hline
\end{tabular}


Notas:

AEspécies ameaçadas segundo a Lista Nacional das Espécies da Fauna Brasileira Ameaçada de Extinção (MMA, 2014), BEspécies ameaçadas segundo a lista vermelha das espécies ameaçadas globalmente da IUCN (IUCN, 2018), *Espécies encontradas no Cerrado com centro de distribuição na Amazônia segundo Silva (1996), nomenclatura segundo o Comitê Brasileiro de Registros Ornitológicos (Piacentini et al., 2015). Endemismos: ENC - espécies de aves endêmicas do Cerrado (Silva 1997; Silva e Santos, 2005), ENA - espécies de aves endêmicas da Amazônia (Stotz, 1996). Nível de ameaça: NT - quase ameaçada, VU - vulnerável à extinção, EN - em perigo de extinção. Status migratório: VN - visitante do Hemisfério Norte.

\section{Discussão}

A região da llha do Bananal/Cantão destaca-se por ser o principal destino para observação de aves no Tocantins e um dos principais do Brasil, devido a elevada riqueza, número de endemismos e de espécies ameaçadas. Soma-se a isso o fato do observador encontrar um número significativo de aves Amazônicas e do Cerrado, bem como algumas espécies migratórias neárticas.

Os avituristas viajam para ver espécies em particular, mas preferem as raras e ameaçadas, bem como áreas com elevado endemismo ou grande riqueza de espécies (HVENEGAARD, 2002; BOOTH et al., 2011). Na região da llha do Bananal/Cantão as espécies endêmicas estão entre os principais alvos pelo fato de terem uma distribuição restrita, neste grupo se destacam quatro espécies, o joão-do-araguaia Synallaxis simoni com incidência limitada ao médio Araguaia, o cardeal-do-araguaia Paroaria baeri com centro de distribuição na Ilha do Bananal e o chororó-de-goiás Cercomacra ferdinandi que ocorre apenas na bacia do Tocantins-Araguaia e encontra-se ameaçado devido a perda e alteração de habitat em razão do barramento dos rios, e uma espécie nova de Furnariideo do gênero Certhiaxis ainda não descrita pela ciência. Em segundo lugar estão as espécies ameaçadas, como o jacu-de-barriga-castanha Penelope ochrogaster, o pica-pau-doparnaíba Celeus obrieni e o arapaçu-barrado-do-xingu Dendrocolaptes retentus ou quase-ameaçadas como o pato-corredor Neochen jubata, relativamente comuns na região e facilmente observadas.

Steven et al., (2013) demonstraram que os observadores de aves geram uma importante receita para as áreas protegidas o que contribui para a conservação de espécies ameaçadas. Na região de estudo, o aporte ao conhecimento ornitológico realizado pelos observadores de aves foi significativo, tanto em termos quantitativos e qualitativos, incrementando respectivamente a lista documentada de aves, como o de espécies ameaçadas e quase-ameaçadas ainda não registradas na região. A visitação de localidades ainda desconhecidas por pesquisadores e a afluência de observadores a determinadas regiões em diferentes períodos do ano tem contribuindo por exemplo, com novos registros e o reconhecimento do declínio de algumas populações de aves (YOURTH, 2000).

Para muitos, a observação de aves é uma atividade que vai muito além do lazer, e a coleta de dados voluntária por meio do compartilhamento de avistamentos, registros fotográficos e sonoros que alimenta bases de 
dados online (por exemplo: wikiaves e ebird), satisfaz objetivos pessoais e ajudam na construção do conhecimento. Estes observadores exercem a chamada ciência cidadã que tem contribuido com a produção científica e monitoramento da biodiversidade em diversos países (COMANDULLI et al., 2016).

Neste cenário, destaca-se o projeto de ciência cidadã eBird do qual participam vários observadores de aves e profissionais brasileiros. Seu sucesso tem sido tão grande, por promover parcerias coletivas entre especialistas de diversas áreas do conhecimento e por ter alcançado uma fórmula que equaliza a quantidade e qualidade dos dados coletados, dando uma nova dimensão a estes projetos (WOOD et al., 2011). Seu objetivo de obter uma grande quantidade de informações por meio do recrutamento e engajamento desses colaboradores, tem sido exitosa, tornando-se na atualidade uma das maiores fontes de dados sobre a biodiversidade global, aumentando o conhecimento sobre a dinâmica e distribuição das espécies e exercendo um impacto direto sobre a conservação das aves e seus habitats (SULLIVAN et al., 2014).

Ainda que no Brasil a base do conhecimento sobre a ocorrência, distribuição e avaliação do status de conservação da avifauna seja oriunda de trabalhos de prospeção e estudos científicos realizados por ornitólogos, e que muitos destes profissionais também são entusiastas e praticantes da observação de aves, o país tem experimentado um crescimento superlativo do número de praticantes amadores que demandam produtos e serviços que movimentam a economia e oportunizam altenativas de renda para comunidades locais em destinos de norte a sul do país. Investimentos tem sido feitos em divulgação, infraestrutura e serviços. Hoje o Brasil abriga a maior feira de observadores de aves da América Latina, o Avistar Brasil; cresce o número de pousadas, muitas delas em locais remotos e de torres de observação que permitem contemplar espécies acima da copa das árvores; empresas com guias especializados, muitos deles bilingues, visando atender o crescente número de estrangeiros; além do mercado de eletrônicos, equipamentos fotográficos, literatura especializada, viajens, locação de veículos, entre outros, gerando empregos e fazendo girar a economia em todos as esferas.

Independente da região, em geral, as unidades de conservação são os destinos preferenciais para prática da observação de aves no Brasil (FIGUEIREDO, 2003; BRASIL, 2005) e nos Estados Unidos (MOURÃO, 2004; BRASIL, 2005). No entanto, diante do grande potencial, os parques nacionais brasileiros vem sendo subutilizados para esta prática (BRASIL, 2008), assim como as RPPNs, onde apenas $4 \%$ das 1.182 reservas desta categoria estão engajadas no ecoturismo (PEGAS; CASTLEY, 2014). $\mathrm{Na}$ região da llha do Bananal/Cantão, das sete unidades de conservação, apenas a RPPN Canguçu e o Parque Estadual do Cantão oferecem infraestrutura ao ecoturista, fornecendo conforto e possibilitando o registro de diversas espécies em ambientes bem preservados. Neste seguimento ecoturístico as unidades de conservação que permitem o uso público desempenham um importante papel, pois além da função ambiental, incluem a função social ao permitir a realização de atividades educativas, recreativas 
e geradoras de conhecimento (PARDINI, 2012).

Portanto, a combinação entre atrativos naturais que incluem ambientes bem preservados e espécies singulares, somada a disponibilidade de infraestrutura, contribuem significativamente para que os observadores de aves possam lograr seus objetivos e contribuir com informações valiosas sobre a avifauna brasileira. $O$ incremento desta atividade ecoturística, praticada em consonância com os preceitos sócioambientais tende a gerar cada vez mais ganhos para a ciência e a economia, melhorando a qualidade de vida das comunidades e promovendo a conservação da biodiversidade.

\section{Referências}

ALEXANDRINO, E. R.; QUEIROZ, O. T. M. M.; MASSARUTTO, R. C. O potencial do municipio de Piracicaba (SP) para o turismo de observação de aves (Birdwatching). Revista Brasileira de Ecoturismo, São Paulo, v.5, n.1, p.27-52, 2012.

ALMEIDA, M. P. S. R.; BAHIA, M. C.; NELSON, S. P. Observação de aves no Refúgio de Vida Silvestre Metrópole da Amazônia: uma contribuição para a conservação ambiental da unidade e ao desenvolvimento turístico do Estado do Pará. Revista Brasileira de Ecoturismo, São Paulo, v.9, n.3, p.544-574, 2016.

BOOTH, J. E.; GASTON, K.J.; EVANS, K. L.; ARMSWORTH, P.R. The value of species rarity in biodiversity recreation: A birdwatching example. Biological Conservation v.144, n.11, p.2728-2732, 2011.

BRASIL. Ministério do Turismo. Plano Aquarela: marketing turístico internacional do Brasil. Embratur/Mintur, Brasília, 2005.

BRASIL, Ministério do Meio Ambiente. Programa de Turismo nos Parques. MMA/ICMBio/EMBRATUR, Brasília, 2008.

CNUC - Cadastro Nacional de Unidades de Conservação. Disponível em: $<$ http://www.mma.gov.br/areas-protegidas/cadastro-nacional-de-ucs>.

Acesso em 07/02/2019.

COMANDULLI, C.; MICHALIS, V.; GILLIAM, C.; ALTENBUCHNER. J.; STEVENS, M.; LEWIS, J.; HAKLAY, M. Ciência Cidadã Extrema: Uma Nova Abordagem. Biodiversidade Brasileira, v.6, n.1, p.34-47, 2016.

CROZARIOL, M. A.; LEITE, G. A. Primeiro registro documentado e aumento na distribuição do topetinho-vermelho, Lophornis magnificus (Vieillot, 1817), para o Estado do Tocantins, Brasil. Revista Brasileira de Ornitologia, v.18, n.1, p.59-60, 2010.

DIAS, R. A biodiversidade como atrativo turístico: o caso do Turismo de Observação de Aves no município de Ubatuba (SP). Revista Brasileira de Ecoturismo, São Paulo, v.4, n.1, p.111-122, 2011. 
DIAS, R.; FIGUEIRA, V. O turismo de observação de aves: um estudo de caso do município de Ubatuba/SP-Brasil. Revista de Estudos Politécnicos, v.8, n.14, p.85-96, 2010.

DORNAS, T. Compilação dos registros de quelônios, crocodilianos e aves do Estado do Tocantins: biodiversidade e lacunas de conhecimento. 2009. 220f. (Dissertação de Mestrado) - Programa de Pós Graduação em Ciências do Ambiente - Palmas: Universidade Federal do Tocantins. 2009.

DORNAS, T.; PINHEIRO, R. T. Ilha do Bananal e Planície do Cantão. In: VALENTE, R. M.; SILVA, J. M. C.; STRAUBE, F. C.; NASCIMENTO, J. L. X. (Org) Conservação de Aves Migratórias Neárticas no Brasil. Belém, 2011.

FARIAS, G. B. A observação de aves como possibilidade ecoturística. Revista Brasileira de Ornitologia, v.15, n.3, p.474-477, 2007.

FARIAS, G. B.; CASTILHO, C. J. M. Observação de aves e ecoturismo em Itamaracá (PE): instrumentos para o desenvolvimento sustentável. Sociedade \& Natureza, v.18, n.35, p.35-53, 2007.

FIGUEIREDO, L. F. A. A observação de aves: esporte, lazer, ciência e arte. 2003. Disponível em: <http://www.ceo.org.br/>

HVENEGAARD, G. T. Birder specialization differences in conservation involvement, demographics, and motivations. Human Dimensions of Wildlife, v.7, n.1, p.21-36, 2002.

IUCN. IUCN Red List of Threatened Species. 2018. Disponível em: $<$ www.iucnredlist.org $>$. Acesso em 05/02/2019.

LEWINSOHN, T. M.; PRADO, P. I. Biodiversidade Brasileira: síntese do estado atual do conhecimento. São Paulo: Editora Contexto, 2002. 176pp.

MCFARLANE, B. L. Specialization and motivations of birdwatchers. Wildife Society Bulletin, v.22, p.361-370, 1994.

MCFARLANE, B. L.; BOXAL, P. C. Participation in wildlife conservation by Birdwatchers. Human Dimensions of Wildlife, vol.1, n.3, p.1-14, 1996.

MEDEIROS, R.; YOUNG; C. E. F.; PAVESE, H. B.; ARAÚJO, F. F. S. Contribuição das unidades de conservação brasileiras para a economia nacional. Sumário Executivo. Brasília: UNEP-WCMC, 2011. 44pp.

MMA/ELETRONORTE/PROAVES. Plano de Manejo do Parque Nacional do Araguaia. Brasília, 2001. 133pp.

MINISTÉRIO DO MEIO AMBIENTE. Portaria n. 444, de 17 de dezembro de 2014. Lista nacional oficial de espécies da fauna ameaçadas de extinção. Diário Oficial da União, Brasília, n. 245, 18 de dezembro de 2014. Seção I, p.121-126.

MOSS, S. A bird in the bush: A social history of birdwatching. London: Aurum Press,2004.

MOURÃO, R. M. F. (org). Manual de melhores práticas para o ecoturismo - turismo sustentável: atividades na natureza. Rio de Janeiro: FUNBIO; Instituto ECOBRASIL, 2004. 58 pp. 
PARDINI, H. O Desafio do Uso Público nas Unidades de Conservação Brasileiras. In: Unidades de Conservação no Brasil: O Caminho da Gestão para Resultados. São Carlos: RiMa Editora, 2012.

PEGAS, F. V.; CASTLEY, J. G. Ecotourism as a conservation tool and its adoption by private protected areas in Brazil. Journal of Sustainable Tourism, v.22, n.4, p.604-625, 2014.

PIACENTINI, V. Q. et al. Lista comentada das aves do Brasil pelo Comitê Brasileiro de Registros Ornitológicos. Revista Brasileira de Ornitologia, v.23, n.2, p.91-298, 2015.

PINHEIRO, R. T. Avifauna do corredor de biodiversidade do Araguaia: distribuição e conservação na área de proteção ambiental llha do Bananal/Cantão. Revista Carbono Social, v.1, n. 4, p.65-71, 2007.

PINHEIRO, R. T.; DORNAS, T. New Records and Distribution of Kaempfer's Woodpecker Celeus obrieni. Revista Brasileira de Ornitologia, v.16, n.2, p.167-169, 2008.

PINHEIRO, R. T.; DORNAS, T. Novos registros ornitológicos para o Parque Estadual do Cantão: distribuição e conservação da avifauna do ecótono Amazônia-Cerrado. Revista Brasileira de Ornitologia, v.17, n.1, p.73-76, 2009a.

PINHEIRO, R. T.; DORNAS, T. Distribuição e conservação das aves na região do Cantão, Tocantins: ecótono Amazônia/Cerrado. Biota Neotropica, v.9, n.1, p.187-205, 2009b.

PIVATTO, M. A. C.; SABINO, J. Recomendações para Minimizar Impactos à Avifauna em Atividades de Turismo de Observação de Aves. Atualidades Ornitológicas, v.128, p.7-11, 2005.

PIVATTO, M. A. C.; SABINO, J.; FAVERO, S.; MICHELS, I. L. Perfil e viabilidade do turismo de observação de aves no Pantanal Sul e Planalto da Bodoquena (Mato Grosso do Sul) segundo interesse dos visitantes. Revista Brasileira de Ornitologia, v.15, n.4, p.520-529, 2007.

PLÁCIDO, R. A. A. Viabilidade prática de observação de aves em unidades de conservação da Amazônia: um estudo de caso da Área de Relevante Interesse Ecológico (ARIE) Japiim-Pentecoste, município de Mâncio Lima, Acre. 2017. 78f. (Dissertação de Mestrado) - Manaus: INPA. 2017.

RUSCHMANN, D. Turismo e planejamento sustentável: A proteção do meio ambiente. Campinas - SP: Editora Papirus, 1997. 132 pp.

SANTOS, E. R.; LOLIS, S. F. Análise florística em comunidades florestais nos municípios de Caseara, Marianópolis e Pium, no estado do Tocantins. Carbono Social, v.1, n.2, p.24-31, 2007.

SEMARH, Secretaria de Meio Ambiente e Recursos Hídricos do Estado do Tocantins. GESTO - Gestão das Unidades de Conservação do Estado do Tocantins. 2016. Disponível em: <http://www.gesto.to.gov.br/> Acesso em 04/02/19. 
SEPLAN . Atlas do Tocantins, subsídios ao planejamento à gestão territorial, 5o ed. Palmas: Secretária de Planejamento do Estado do Tocantins. 2008.

SILVA, J. M. C. Distribuition of Amazonian and Atlantic birds in gallery forest of the Cerrado region, South America. Ornitologia Neotropical, v.7, n.1, p.1-18, 1996.

SILVA, J. M. C. Endemic bird species and conservation in the Cerrado Region, South America. Biodiversity and Conservation, v.6 n.3. p.435-450, 1997.

SILVA, J. M. C.; SANTOS, M. P. D. A importância relativa dos processos biogeográficos na formação da avifauna do Cerrado e de outros biomas brasileiros. In: SCARIOT, A.; SOUSA FILHO, J. C.; FELFILI, J. M. (orgs). Cerrado: Ecologia, Biodiversidade e Conservação. Ministério do Meio Ambiente, Brasília, p.224-233, 2005.

STEVEN, R.; CASTLEY, J. G; BUCKLEY, R. Tourism revenue as a conservation tool for threatened birds in protected areas. Plos One, v. 8, n.5, p.1-8, 2013.

STOTZ, D. F.; FITZPATRICK, J. W.; PARKER III, T. A. Neotropical Birds: ecology and conservation. Chicago, Illinois: University of Chicago Press, 1996.

TOCANTINS. Plano de Manejo do Parque Estadual do Cantão. Palmas: Secretaria do Planejamento e Meio Ambiente do Estado do Tocantins, 2004.

YOURTH, H. Watching vs. Taking. World Watch, v.13, p.12-23, 2000.

WOOD, C.; SULLIVAN, B.; ILIFF, M.; FINK, D.; KELLING, S. EBird: engaging birders in science and conservation. PLoS Biology, v.9, n. 12, p.15, 2011.

\section{Agradecimentos}

Agradeço o Sr. Dieyson Rodrigues de Moura pela elaboração da figura 1.

Renato Torres Pinheiro: Universidade Federal do Tocantins, Palmas, TO, Brasil.

E-mail: renaxas@hotmail.com

Link para o currículo Lattes: http://lattes.cnpq.br/5050256632943011

Data de submissão: 28 de fevereiro de 2019

Data de recebimento de correções: 05 de abril de 2019

Data do aceite: 05 de abril de 2019

Avaliado anonimamente 